\title{
Christophe Loir, Bruxelles néoclassique. Mutation d'un espace urbain 1775-1840
}

\section{Annie Duprat}

\section{(2) OpenEdition Journals}

Édition électronique

URL : https://journals.openedition.org/ahrf/11768

DOI : $10.4000 /$ ahrf. 11768

ISSN : 1952-403X

Éditeur :

Armand Colin, Société des études robespierristes

Édition imprimée

Date de publication : 1 septembre 2010

Pagination : 223-225

ISBN : 978-2-200-92633-5

ISSN : 0003-4436

Référence électronique

Annie Duprat, "Christophe Loir, Bruxelles néoclassique. Mutation d'un espace urbain 1775-1840 »,

Annales historiques de la Révolution française [En ligne], 361 I juillet-septembre 2010, mis en ligne le 22 mars 2011, consulté le 23 avril 2022. URL : http://journals.openedition.org/ahrf/11768 ; DOI : https:// doi.org/10.4000/ahrf.11768

Ce document a été généré automatiquement le 23 avril 2022.

Tous droits réservés 


\title{
Christophe Loir, Bruxelles néoclassique. Mutation d'un espace urbain 1775-1840
}

\author{
Annie Duprat
}

\section{RÉFÉRENCE}

Christophe Loir, Bruxelles néoclassique. Mutation d'un espace urbain 1775-1840, Bruxelles, CFC-Éditions, 312 p., ISBN 978-2-930018-67-6, $34 €$

1 Le projet du nouvel ouvrage de Christophe Loir, professeur à l'Université libre de Bruxelles, est d'expliquer au lecteur comment l'architecture de la ville capitale de la Belgique s'est radicalement métamorphosée entre les années 1760-1780 et les années 1830. Historien de l'art et spécialiste de Bruxelles, Christophe Loir a déjà fait paraître en 2004 une étude sur L'émergence des beaux-arts en Belgique: institutions, artistes, public et patrimoine de 1773 à 1835, dont le présent ouvrage est l'aboutissement. En effet, sur plus de 300 pages sur papier glacé et à l'aide d'une centaine de reproductions en noir et blanc et en couleurs, l'auteur se propose de démontrer, preuves à l'appui, comment une ville qui n'avait pas encore subi, au milieu du XVIII ${ }^{\mathrm{e}}$ siècle, de plans d'urbanisme a vécu une métamorphose radicale en une soixantaine d'années. Deux espaces distincts doivent être mis en exergue : l'arasement des remparts, remplacés par des boulevards extérieurs et des promenades plantées d'arbres, et la création des voies de chemin de fer et des gares qui font de Bruxelles une capitale européenne, avant même la grande révolution des transports de la fin du XIX ${ }^{\mathrm{e}}$ siècle. Certes, le sort de Bruxelles n'est pas exceptionnel en ce domaine, puisque la plupart des villes d'Europe détruisent les remparts médiévaux qui pouvaient encore subsister et construisent voies ferrées et gares. Mais il était bon de faire le point concernant une capitale dont la renommée repose davantage sur les merveilles de l'architecture et du décor baroque et art 
nouveau de la fin du $\mathrm{XIX}^{\mathrm{e}}$ siècle et du début du $\mathrm{Xx}^{\mathrm{e}}$ siècle que sur l'architecture néoclassique que le livre de Christophe Loir nous invite à découvrir avec lui.

Le livre s'ouvre sur deux visites: Bruxelles vers 1775 et Bruxelles vers 1840. Pour chacune des deux dates, l'auteur reproduit des plans (le plan de Martin du Tailly, 1748 et une lithographie de Canelle, 1850) dont il décrit et explicite les principaux traits : des toitures et des clochers entassés et comme confinés à l'intérieur de remparts percés de sept portes, des rues tortueuses, une dizaine de places publiques à destination de marchés (marché aux grains, aux chevaux, aux bestiaux, etc...) et des espaces non bâtis répartis de manière anarchique au cœur de l'ensemble. La Bruxelles de 1750 ressemble à la plupart des villes anciennes d'Europe, à l'exception de Paris et des sièges des généralités qui connaissaient depuis le $\mathrm{XVII}^{\mathrm{e}}$ siècle des embellissements et une politique d'urbanisme qui s'est déployée au XVIII ${ }^{\mathrm{e}}$. L'auteur utilise également les livres de voyage pour nous promener dans cette ancienne Bruxelles, du quartier de la Cour, situé dans la haute ville à celui de la Grand' Place située dans le bas de la ville, et du quartier du Port aux différentes institutions ecclésiastiques et aux œuvres d'art qui y sont conservées. Les descriptions contemporaines rendent compte d'une ville aux rues encombrées et mal pavées, qui présente tous les traits d'une ville médiévale.

3 En 1840, un événement majeur s'est déjà produit: l'arrivée du chemin de fer et la construction de la gare du Midi. Le plan reproduit montre la disparition des remparts, et la mise en confrontation de l'ancienne porte de Schaerbeek (illustration de 1783) avec le poste d'octroi (illustration de 1830) montre mieux qu'un long discours tout le chemin parcouru. Les guides et livres de voyages sont alors très nombreux et Christophe Loir en donne de larges extraits très intéressants. Il cite également les commentaires des voyageurs, en particulier ceux d'Emerson Tennent, homme politique et voyageur irlandais (1804-1869). Tous les témoignages contemporains conseillent la visite à partir du haut de la ville, du Quartier Royal au boulevard de Waterloo, puis, vers le bas, de la Monnaie à la Grand'Place avec ses théâtres et sa place des martyrs.

4 Comme un guide touristique, le livre se poursuit par la présentation de sept promenades, à chaque fois présentées à l'aide d'un plan et de nombreuses reproductions figurées (tableaux, lithographies) qui exposent les transformations entre les deux dates considérées. L'augmentation de la population bruxelloise justifie la construction de plusieurs milliers de maisons, mais c'est le développement de l'urbanisme et le changement du goût qui expliquent la disparition des maisons à façade-pignon au profit des maisons à façade-corniche, qui s'insèrent toutes dans une enfilade rectiligne. Les bâtiments publics, très vastes, empruntent beaucoup à l'esthétique antique, avec des portiques et des arcades. Tout cela témoigne de l'accession de Bruxelles au rang de métropole européenne, avant même son épanouissement architectural à la fin du XIX ${ }^{e}$ siècle, à l'époque de l'art nouveau. Livre écrit d'une plume légère, cet ouvrage est aussi un livre savant, puisqu'il publie une imposante bibliographie, avec en particulier de nombreuses sources manuscrites. 